\title{
DIVERSITY: CHALLENGES AND OPPORTUNITIES
} IN INFANCY

\author{
SUSAN MCDONOUGH \\ University of Michigan \\ HIRAM E. FITZGERALD \\ Michigan State University
}

This special issue of the Infant Mental Health Journal presents the plenary addresses from WAIMH's 7th World Congress in Montreal, Canada (2000). As we noted in the program booklet for that congress, the field of infant mental health coalesces around three common assumptions: infant behavior cannot be viewed separately from relationships with others; infants' most important relationships are with their primary caregivers; and infant caregivers have relationships with others in their social contexts. These assumptions rest on such historical reminders that infants are born into a social world (Rheingold, 1968), which consists of reciprocal relationships (Bell, 1968), (especially) with primary caregivers (Winnicott, 1964), who may or may not have unresolved issues that construct barriers to the development of secure social-emotional relationships (Fraiberg, Adelson, \& Shapiro, 1975). All of these characterizations provide a basis for understanding that infant mental health is grounded in the reciprocal interactions that infants have with others within the extraordinarily diverse contexts in which infants live and negotiate the world. Infants, caregivers, extended family members, and the broader social and cultural networks in which these families are embedded, provide the contexts that influence social and emotional development and generate issues relevant to infant mental health (Fitzgerald \& Barton, 2000).

If there is any common theme cutting across all of the contexts within which human infants live and thrive or atrophy and die, it is diversity. The theme of the 7th World Congress, "Diversity: Challenges and Opportunities in Infancy," captured the Program Committee's desire to examine contemporary knowledge about the infant in multiple contexts. The congress subthemes were selected to reflect trends in research, clinical practice, and social policy, or to draw attention to issues that should enter into the domain of topics that define modern "trends." The subthemes and plenary speakers whose works are published in this issue of the Infant Mental Health Journal were "Brain-Behavior Interface" (Megan Gunnar, United States), "De-

Direct correspondence to: Susan McDonough, School of Social Work, University of Michigan, Ann Arbor, MI 48109; e-mail: scmcdono@umich.edu; or Hiram Fitzgerald, Michigan State University, 22 Kellogg Center, University Outreach, East Lansing, MI 48824; e-mail: fitzger9@msu.edu.

INFANT MENTAL HEALTH JOURNAL, Vol. 24(3), 193-194 (2003)

(C) 2003 Michigan Association for Infant Mental Health

Published online in Wiley InterScience (www.interscience.wiley.com). DOI: 10.1002/imhj.10051 
velopment and Psychopathology" (Peter Fonagy, United Kingdom), "Culture and Context" (Marie Rose Moro, France), and "Infants and Children Living in Poverty" (Astrid Berg, South Africa). Their articles reflect diversity in approach (science, theory, practice), culture (four countries), and discipline (psychology, psychiatry).

In addition to publishing the four traditional plenary addresses from the congress, the special issue also includes the presentation on coparenting offered by the $2000 \mathrm{New}$ Investigator Awardee (Laurie Van Egeren, United States). Finally, Yvon Gauthier's Presidential Address, challenges everyone associated with the field of infant mental health to actively participate in aggression and violence reduction, drawing on the field's disciplinary and international diversity, and the interrelated domains of science, practice, and policy. We hope this new approach to publishing material from the WAIMH World Congresses will help to highlight important trends in the scientific, practice, and policy arenas relevant to infant mental health, and thereby provide important input to the evolving definition of infant mental health.

\section{REFERENCES}

Bell, R.Q. (1968). A reinterpretation of the direction of effects in studies of socialization. Psychological Review, 75, 81-95.

Fitzgerald, H.E., \& Barton, L.R. (2000). Infant mental health: Origins and emergence of an interdisciplinary field. In J.D. Osofsky \& H.E. Fitzgerald (Eds.), Handbook of infant mental health: Vol. 1. Perspectives on infant mental health (pp. 1-36). New York: Wiley.

Fraiberg, S., Adelson, E., \& Shapiro, V. (1975). Ghosts in the nursery: A psychoanalytic approach to the problems of impaired infant-mother relationships. Journal of the American Academy of Child Psychiatry, 14, 387-421.

Rheingold, H.L. (1968). The social and socializing infant. In D.A. Goslin (Ed.). Handbook of socialization: Theory and research. Chicago: Rand McNally.

Winnicott, D.W. (1987). The child, the family, and the outside world. Reading: MA: Addison-Wesley (original work published 1964). 